\title{
Serum- and Glucocorticoid-Inducible Kinase 1 Sensitive NF- $\kappa$ B Signaling in Dendritic Cells
}

\author{
Evi Schmid ${ }^{a}$ Nguyen Thi Xuan a,b Naima Zahir ${ }^{a} \quad$ Antonella Russo ${ }^{a}$ Wenting Yang ${ }^{a}$

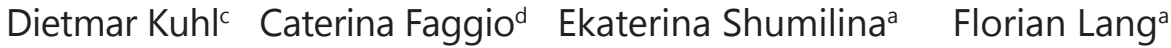

\begin{abstract}
aDepartment of Physiology, University of Tübingen, Tübingen, Germany; 'Institue of Genome Research, Vietnam Academy of Science and Technology, No.18, Hoang Quoc Viet, CauGiay, Hanoi, Vietnam; 'Center for Molecular Neurobiology (ZMNH), Institute for Molecular and Cellular Cognition, University Medical Center Hamburg-Eppendorf, Hamburg-Eppendorf, Germany; ${ }^{d}$ Department of Biological and Environmental Sciences, University of Messina, S.Agata-Messina, Italy
\end{abstract}

\section{Key Words}

$\mathrm{NF}-\mathrm{KB} \cdot \mathrm{IKK} \alpha / \beta \cdot \mathrm{PI} 3$ kinase $\cdot \mathrm{NDRG1} \cdot$ Phagocytosis

\begin{abstract}
:
Background/Aims: Dendritic cells (DCs), antigen-presenting cells linking innate and adaptive immunity, are required for initiation of specific $T$ cell-driven immune responses. Phosphoinositide-3-kinase (PI3K) suppresses proinflammatory cytokine production in DCs, which limits T helper (Th1) polarization. PI3K is in part effective by downregulation of transcription factor NF-KB. Downstream signaling elements of PI3K include serum- and glucocorticoid-inducible kinase 1 (SGK1) and its phosphorylation target N-myc downstream regulated gene 1 (NDRG1). The present study explored whether SGK1 and NDRG1 play a role in the regulation of NF- $\mathrm{KB}$ and DC-maturation. Methods: DCs were isolated from bone marrow (BMDCs) or spleen of mice lacking functional SGK1 $\left(\mathrm{sgk1}^{--}\right)$and corresponding wild type mice $\left(s g k 1^{+/+}\right)$. Protein abundance was determined by Western blotting. Transcription was inhibited by siRNA. Abundance of maturation markers was quantified by flow cytometry. FITC-dextran uptake was determined to quantify phagocytosis. Results: NDRG1 was similarly expressed in $s g k 1^{+/+}$and $s g k 1^{-/ B M D C s}$, but SGK1-dependent phosphorylation of NDRG-1 was decreased in $s g k 1^{-/ B M D C s}$. Silencing of NDRG1 in $s g k 1^{+/+} B M D C s$ as compared to control empty vectortreated BMDCs enhanced nuclear abundance of NF-KB subunit p65. Moreover, the abundance

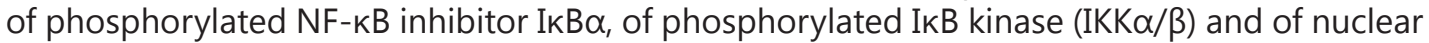

E. Schmid and N.T. Xuan contributed equally and thus share first authorship; E. Shumilina and F. Lang contributed equally and thus share senior authorship. 
p65 were significantly higher in $s g k 1^{-/}$BMDCs than in $s g k 1^{+/+}$BMDCs. Expression of maturation markers, MHC II, and CD86, was significantly larger and phagocytic capacity was significantly lower in $s g k 1^{-/}$than in $s g k 1^{+/+}$BMDCs. Expression of CD86 and MHCII was also significantly

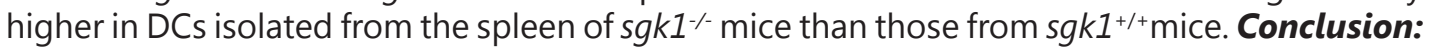
SGK1 and NDRG1 participate in the regulation of NF-KB signaling in and maturation of DCs.

Copyright $\odot 2014$ S. Karger AG, Basel

\section{Introduction}

Dendritic cells (DCs) are professional antigen presenting cells (APCs) linking innate and acquired immunity [1-5]. Following stimulation, DCs express and release proinflammatory cytokines and chemokines, up-regulate the expression of MHC class I and II, costimulatory and adhesion molecules, and migrate to the nearest lymph node where they induce the activation and proliferation of naïve $\mathrm{T}$ cells $[1,6]$.

Inflammatory processes are required to eliminate pathogens but by the same token excessive inflammation is detrimental to the host. Phosphoinositide 3 kinase (PI3K) belongs to the gate-keeping system, preventing excessive proinflammatory responses in DCs. During DC stimulation, PI3K is activated and prevents potential immunopathological effects of enhanced DC-mediated Th1 responses [7]. Genetic knockout of p85 $\alpha$, the regulatory subunit of PI3K, enhances the resistance of mice to Leishmania major, a pathogen controlled by DCmediated Th1 development [7].

PI3K downstream signaling includes the kinase PDK1 (3-phosphoinositide-dependent kinase) [8]. The phenotype of DCs derived from PDK1 hypomorphic mice, which express about $10 \%$ of wild type levels of the enzyme, includes reduced Toll like receptor-induced macropinocytosis but enhanced antigen presentation, increased levels of costimulatory molecules and enhanced production of cytokines (IL-12 and IL-10) [8].

PDK1 activates downstream kinases such as protein kinase B (PKB/Akt) and serumand glucocorticoid-inducible kinase (SGK) isoforms. The role of Akt1 seems to be restricted to promoting Bcl-2-dependent survival of DCs [9]. Akt2 is an important regulator of $\mathrm{Ca}^{2+}$ signaling and migration in DCs [10]. SGK1 has been most recently shown to participate in the signaling inducing pathogenic Th17 cells which drive autoimmune disease [11, 12]. DCs and NF- $\kappa B$ signaling both participate in the regulation of Th17 cells $[13,14]$. The role of SGK1 in DCs has, however not been investigated yet.

$\mathrm{PI} 3 \mathrm{~K}$ has been shown to negatively regulate NF- $\mathrm{BB}$ in monocytes, macrophages and DCs

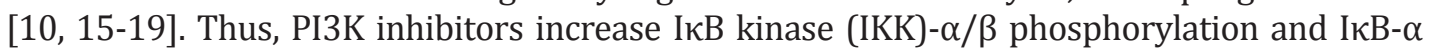
degradation with a concomitant increase in NF- $\kappa B$ nuclear translocation [15].

IKK- $\alpha / \beta$ phosphorylation and thus NF- $\kappa B$ signaling could be enhanced by SGK1 [20-24]. On the other hand, a specific substrate of SGK1, NDRG-1 (N-myc downstream regulated gene 1), which is phosphorylated by SGK1 (and not by Akt) at three different sites [25], has been shown to attenuate NF- $\kappa B$ signaling [26], when phosphorylated at two SGK1-dependent sites [27].

The present study has thus been performed to elucidate whether SGK1 participates in the regulation of DC functions via NDRG1 and NF- $\kappa B$.

\section{Materials and Methods}

Animals

All animal experiments were conducted according to the German law for the welfare of animals and were approved by local authorities. As described previously [28], a conditional targeting vector was generated from a 7-kb fragment encompassing the entire transcribed region on 12 exons. The neomycin resistance cassette was flanked by two loxP sites and inserted into intron 11. Exons 4-11, which code for the sgk1 domain, were "floxed" by inserting a third loxP site into intron 3. Targeted R1 ES cells were transiently transfected with Cre 
Schmid et al.: SGK1 Sensitive Regulation of NF-kB Signaling in DCs

recombinase. A clone with a recombination between the first and the third loxP site (type I recombination) was injected into C57BL/6 blastocytes. Male chimeras were bred to 129/SvJ females. Heterozygous sgk1-deficient mice were backcrossed to $129 / \mathrm{SvJ}$ wild-type mice for two generations and then intercrossed to generate homozygous $s g \mathrm{k}^{-/-}$and $s g k 1^{+/ /}$littermates. The animals were genotyped by PCR using standard methods.

Culture of bone marrow dendritic cells

Dendritic cells (DCs) were cultured from bone marrow of 8-12 week old female and male mice [29]. Bone marrow derived cells were flushed out of the cavities from the femur and tibia with PBS. Cells were then washed twice with RPMI and seeded out at a density of $2 \times 10^{6}$ cells $/ 10 \mathrm{ml}$ per $60-\mathrm{mm}$ dish. Cells were cultured for 8 days in RPMI 1640 (GIBCO, Carlsbad) containing: 10\% FCS, 1\% penicillin/streptomycin, 1\% non-essential amino acids (NEAA) and $0.05 \% \beta$-mercaptoethanol [30]. Cultures were supplemented with GM-CSF ( $35 \mathrm{ng} / \mathrm{mL}$, Preprotech Tebu) and fed with fresh medium containing GM-CSF on days 3 and 6 . At day $7,>80 \%$ of the cells expressed CD11c, which is a marker for mouse DCs. No statistically significant difference in CD11c-expression was observed between $s g k 1^{-/}$and $s g k 1^{+/+}$DCs. Experiments were performed on DCs at days $7-9[31]$.

\section{Isolation of splenic $D C s$}

Dendritic cells were isolated from the spleen of 8-12 weeks old female and male mice according to the protocol of Stagg et al. [32]. Briefly, single-cell suspensions were prepared by pressing mouse spleen through a gauze cell strainer (BD Pharmingen, Heidelberg, Germany) and washing in RPMI 1640 (GIBCO, Carlsbad, Germany) containing: $10 \%$ FCS, 1 \% penicillin/streptomycin, $1 \%$ glutamine, $1 \%$ non-essential amino acids (NEAA) and $0.05 \% \beta$-mercaptoethanol. After overnight incubation nonadherent cells were collected and DCs were purified by centrifugation over a $13.7 \%(\mathrm{w} / \mathrm{v})$ metrizamide discontinuous gradient.

\section{Immunostaining and flow cytometry}

Cells $\left(4 \times 10^{5}\right)$ were incubated in $100 \mu$ FACS buffer (phosphate buffered saline (PBS) plus $0.1 \%$ FCS) containing fluorochrome-conjugated antibodies at a concentration of $10 \mu \mathrm{g} / \mathrm{ml}$ [33]. A total of $2 \times 10^{4}$ cells were analyzed. The following antibodies (all from BD Pharmingen, Heidelberg, Germany) were used for staining: FITC-conjugated anti-mouse CD11c, clone HL3 (Armenian Hamster IgG ${ }_{1}, \lambda 2$ ), PE-conjugated antimouse CD86, clone GL1 (Rat $\operatorname{IgG}_{2 a^{a}} \kappa$ ), and PE-conjugated rat anti-mouse I-A/I-E, clone M5/114.15.2 (IgG2b, к). After incubating with the antibodies for 60 minutes at $4^{\circ} \mathrm{C}$, the cells were washed twice and resuspended in FACS buffer for flow cytometric analysis.

\section{Silencing of NDRG1}

Specific siRNA sequences for NDRG1 (Silencer® Select Pre-Designed siRNA, Ambion - life technologies) and negative control (Silencer® Select Negative Control \#1 siRNA, Ambion - life technologies, Catalog \# 4390843) were synthesized and annealed by the manufacturer. siRNA transfection was carried out using the GeneSilencer siRNA transfection reagent (Genlantis, San Diego, CA,USA). 4 × $10^{6}$ cells were washed and plated in 6-well plates in $1 \mathrm{ml}$ of serum-free RPMI 1640. The NDRG1 siRNA and the negative control (1000 ng/well) were incubated with GeneSilencer reagent following the manufacturer's protocol. Transfection mixture was then added to the wells and incubated for 24 hours. The efficiency of silencing was assessed with RT-PCR.

\section{DC phagocytosis assay}

DCs $\left(10^{6}\right.$ cells $\left./ \mathrm{ml}\right)$ were suspended in prewarmed serum-free RPMI 1640 medium, pulsed with FITC-conjugated dextran (Sigma-Aldrich, Taufkirchen, Germany) at a final concentration of $1 \mathrm{mg} / \mathrm{ml}$ and incubated for $3 \mathrm{~h}$ at $37^{\circ} \mathrm{C}$. Uptake was stopped by adding ice-cold PBS. The cells were washed three times with ice cold PBS supplemented with 5\% FCS and 0.01\% sodium azide before FACS analysis. DCs were analyzed for the uptake of FITC-dextran [34]. The percentage of FITC-dextran staining following a 5 minute exposure amounted to $2.6 \%$ indicating little binding of FITC-dextran to the cell surface.

\section{Preparation of nuclear and cytosolic extracts}

Nuclear and cytosolic extracts were prepared as described previously [35]. DCs from $s g k 1^{+/+}$and $s g k 1^{\%}$ mice were centrifuged for $5 \mathrm{~min}$ at $408 \mathrm{~g}$ at $4^{\circ} \mathrm{C}$. The pellet was washed in ice cold phosphate-buffered saline 
(PBS) and cells were lysed in 500ml buffer A (10 mM HEPES, $1.5 \mathrm{mM} \mathrm{MgCl2}, 10 \mathrm{mM} \mathrm{KCl}, 0.5 \mathrm{mM}$ DTT, 0.05\% NP-40, pH 7.9) containing protease inhibitor cocktail (Sigma-Aldrich, Taufkirchen, Germany) and incubated on ice for $10 \mathrm{~min}$. Cell lysates were centrifuged at $3,000 \mathrm{~g}$ for $10 \mathrm{~min}$ at $4^{\circ} \mathrm{C}$. Supernatants containing the cytosolic fraction were collected and transferred into a separate tube. Residual pellets containing the nuclei were resuspended in $93.5 \mathrm{ml}$ buffer B (5 mM HEPES, $1.5 \mathrm{mM} \mathrm{MgCl}$ 2, $0.2 \mathrm{mM}$ EDTA, $0.5 \mathrm{mM}$ DTT, 26\% glycerol (v/v), pH 7.9) and $6.5 \mathrm{ml}$ of $4.6 \mathrm{M} \mathrm{NaCl}$ and vortexed for $30 \mathrm{~s}$. After incubation on ice for another $30 \mathrm{~min}$, nuclear lysates were centrifuged at $15,000 \mathrm{~g}$ for $30 \mathrm{~min}$ at $4^{\circ} \mathrm{C}$ to remove nuclear debris. Protein concentrations of cytosolic and nuclear extracts were determined with Bradford (Biorad).

\section{Immunoblotting}

DCs from $s g k 1^{+/}$and $s g k 1 \%$ mice were centrifuged for $5 \mathrm{~min}$ at $408 \mathrm{~g}$ and $4^{\circ} \mathrm{C}$. The pellet was washed in ice cold PBS and resuspended in lysis buffer (Cell Signaling Technology, Inc., New England Biolabs) containing protease inhibitor cocktail (Sigma-Aldrich, Taufkirchen, Germany). After centrifugation for 20 min at 20,000 $\mathrm{g}$ and $4^{\circ} \mathrm{C}$ the supernatant was taken and the protein concentration of the supernatant was determined with Bradford (Biorad). Total protein $(30 \mu \mathrm{g})$ was subjected to $10 \%$ SDS-PAGE. Proteins were transferred to a nitrocellulose membrane (VWR) and the membranes were then blocked for $1 \mathrm{~h}$ at room temperature with $10 \%$ non-fat dried milk in tris-buffered saline (TBS) containing 0.1\% Tween 20. For immunoblotting the membranes were incubated overnight at $4^{\circ} \mathrm{C}$ with antibodies directed against phospho (p)-(Thr346)-NDRG1 (1:1000, Cell Signaling Technology, Inc., New England Biolabs), p-(Ser330)- NRDG1 (1:1000, Cell Signaling Technology, Inc., New England Biolabs), NDRG1 (1:1000, Cell Signaling Technology, Inc., New England Biolabs), NF-kappa-B p65 (1:1000, Cell Signaling Technology, Inc., New England Biolabs), p-(Ser32/36)-IкB $\alpha$ (1:1000, Cell Signaling Technology, Inc., New England Biolabs), p-(Ser176/180)-IKK $\alpha / \beta$ (1:1000, Cell Signaling Technology, Inc., New England Biolabs), and IKK $\beta$ (1:1000, Cell Signaling Technology, Inc., New England Biolabs). A GAPDH antibody (1:1000, Cell Signaling Technology, Inc., New England Biolabs), Lamin A (1:1000, Santa Cruz) or $\beta$-Actin antibody (1:1000, Cell Signaling Technology, Inc., New England Biolabs) were used as loading controls. Specific protein bands were visualized after subsequent incubation with a 1:3000 dilution of anti-rabbit IgG or anti-mouse IgG conjugated to horseradish peroxidase and a Super Signal Chemiluminescence detection procedure (GE Healthcare, UK). Specific bands were quantified by Quantity one software (Bio rad gel doc system, Chemidoc $\mathrm{XRS}$ ). Levels of each protein were expressed as the ratio of signal intensity for the target protein relative to that of GAPDH, Lamin A or $\beta$-Actin.

\section{Real-time PCR}

Total RNA was extracted from mouse dendritic cells in peqGold Trifast (Peqlab, Erlangen, Germany) according to the manufacturer's instructions. After DNAse digestion reverse transcription of total RNA was performed using Transcriptor High Fidelity cDNA Synthesis Kit (Roche Diagnostics, Mannheim, Germany) according to the manufacturer's instructions. Polymerase chain reaction (PCR) amplification of the respective genes were set up in a total volume of $20 \mu$ using $40 \mathrm{ng}$ of cDNA, $500 \mathrm{nM}$ forward and reverse primer and 2x GoTaq ${ }^{\circledR}$ qPCR Master Mix SYBR Green (Promega Corporation, Madison, WI, USA) according to the manufacturer's protocol. Cycling conditions were as follows: initial denaturation at $95^{\circ} \mathrm{C}$ for $5 \mathrm{~min}$, followed by 40 cycles of $95^{\circ} \mathrm{C}$ for $15 \mathrm{sec}, 59^{\circ} \mathrm{C}$ for $15 \mathrm{sec}$ and $72^{\circ} \mathrm{C}$ for $30 \mathrm{sec}$. For the amplification the following primers were used ( $5^{\prime}>3^{\prime}$ 'orientation):

NDRG1,fwACCCTGAGATGGTAGAGGGTCTC; revCCAATTTAGAATTGCATTCCACC

Tbp, fw TATGACCCTATCACTCTGCC rev TCTTGGGCTCCTGTGCCAGAG.

Specificity of PCR products was confirmed by analysis of a melting curve. Real-time PCR amplifications were performed on a CFX96 Real-Time System (Bio-Rad). All experiments were done in duplicate. Amplification of the house-keeping gene Tbp (TATA binding protein) was performed to standardize the amount of sample RNA. Relative quantification of gene expression was achieved using the $\Delta \Delta \mathrm{ct}$ method.

\section{Statistics}

Data are provided as means \pm SEM, $n$ represents the number of independent experiments. All data were tested for significance using Student's unpaired two-tailed $t$-test. Results with $\mathrm{p}<0.05$ were considered statistically significant. 
Fig. 1. Reduced phosphorylation of NDRG-1 in $s g k 1$ 1- DCs. A. Original Western blot of $s g k 1^{+/+}$and $s g k 1^{\%}$ DCs with antibodies directed against phospho (p)-NDRG1 at Thr346 (p-(Thr346)NDRG1) and at Ser330 (p(Ser330)-NDRG1), as well as total NDRG1. Equal protein loading was confirmed with $\beta$-Actin antibody. B. Arithmetic means \pm SEM (n =5-8) of p-(Thr346)-NDRG1/ $\beta$-Actin, $\mathrm{p}$-(Ser330)-NDRG1/ $\beta$-Actin and total NDRG1/ $\beta$-Actin ratio in $s g k 1^{+/+}$(open bars) and $s g k 1 \%$ (closed bars) DCs. ${ }^{*}(\mathrm{p}<0.05), \quad{ }^{* *}(\mathrm{p}<0.01)$, twotailed unpaired $t$-test.
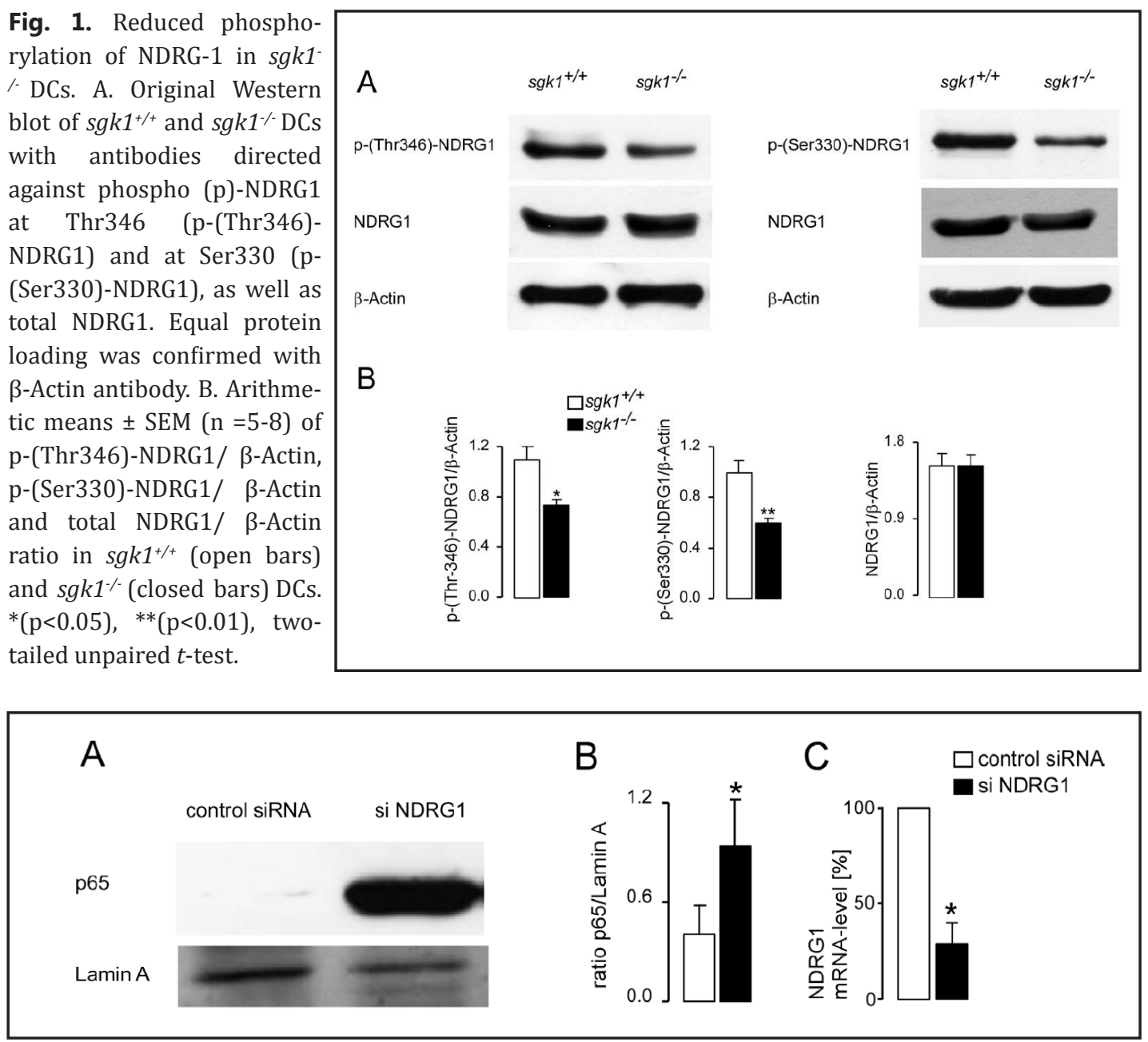

Fig. 2. Enhanced nuclear localization of p65 upon NDRG1 knock-down in $s g k 1^{+/+}$DCs. A. Western blot analysis of nuclear p65 in negative control siRNA- or siNDRG1- transfected DCs. Representative experiments showing p65 band and Lamin A as loading control. B. Arithmetic means $( \pm$ SEM, $n=4)$ of the abundance of nuclear p65 as the ratio to Lamin A in negative control siRNA- (open bars) or siNDRG1- (closed bars) transfected DCs. ${ }^{*}(\mathrm{p}<0.05)$, two-tailed unpaired $t$-test.C. Arithmetic means $( \pm S E M, n=4)$ of the abundance of mRNA encoding NDRG1 in $s g k 1^{+/+}$DCs without (control, empty vector) and with (siNDRG1) silencing of NDRG1 as assessed by real-time PCR using TBP mRNA as a reference gene. Relative mRNA expression in siNDRG1- DCs was normalized to respective values in control cells. ${ }^{*}(\mathrm{p}<0.05)$, two-tailed unpaired $t$-test.

\section{Results}

LosS of SGK1 results in reduced phosphorylation of NDRG1

DCs were obtained from the bone marrow (BM) of SGK1 knockout mice (sgk1\%) and wild-type littermates $\left(s g \mathrm{k1}^{+/+}\right)$. NDRG1 expression and phosphorylation was analyzed in $s g k 1^{+/+}$and $s g k 1 \%$ BMDCs by western blotting. As shown in Fig. 1, NDRG1 expression was not affected by SGK1 deficiency but SGK1-dependent phosphorylation of Thr346 and Ser330 of NDRG-1 was decreased in $s g k 1 \%$ BMDCs.

Knockdown of NDRG1 results in enhanced p65 nuclear localization

Silencing of NDRG1 by siRNA in $s g k 1^{+/+}$BMDCs resulted in an enhanced nuclear abundance of the NF- $\kappa$ B subunit p65 compared to the control empty vector-treated BMDCs (Fig. 2), as analyzed by western blot of the nuclear fraction. The efficiency of NDRG1 was 


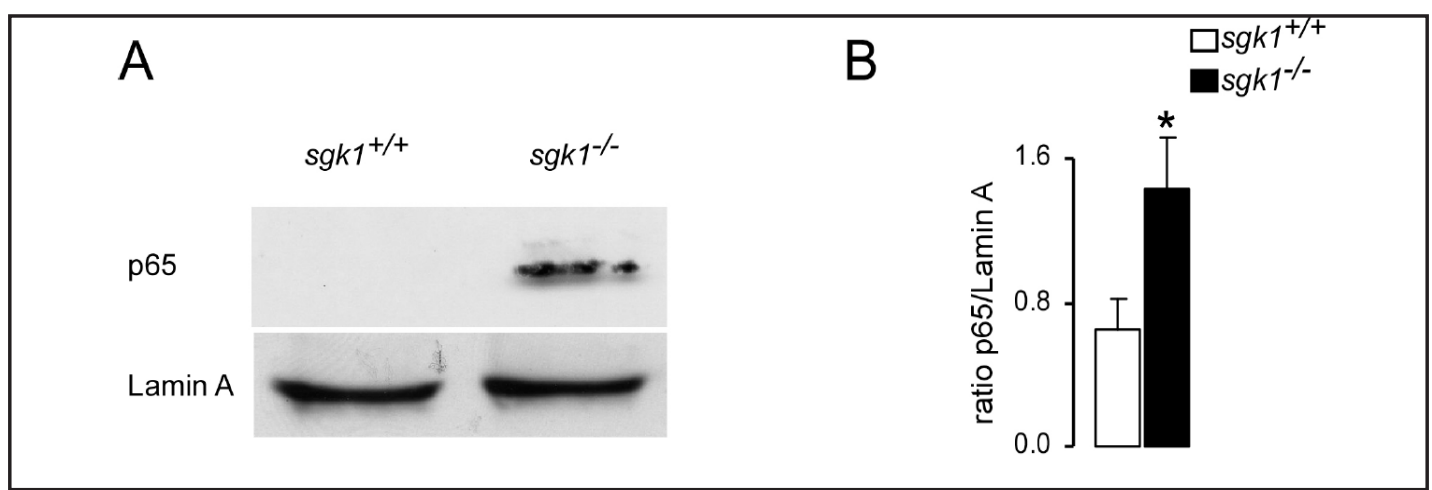

Fig. 3. Enhanced p65 nuclear localization in $s g k 1^{1 /}$ DCs. A. Original Western blot of nuclear p65 in $s g k 1^{+/+}$ and $s g k 1 \%$ DCs. Protein loading was controlled by anti-Lamin A antibody. B. Arithmetic means \pm SEM $(n=5)$ of the abundance of nuclear p65 as the ratio to Lamin A in $s g k 1^{+/+}$(open bars) and $s g k 1^{\%}$ (closed bars) DCs. $*(\mathrm{p}<0.05)$, two-tailed unpaired $t$-test.

Fig. 4. Increased $I K K \alpha / \beta$ phosphorylation in $s g k 1 \%$ DCs. A. Original Western blot of phospho-IKK $\alpha / \beta \quad(\mathrm{p}-\mathrm{IKK} \alpha / \beta)$ and total IKK $\beta$ in $s g k 1^{+/+}$and $s g k 1 \%$ DCs. Protein loading was controlled by GAPDH antibody. B. Arithmetic means \pm SEM ( $n=10-12)$ of the abundance of $\mathrm{p}-\mathrm{IKK} \alpha / \beta$ as the ratio to GAP$\mathrm{DH}$ in $s g k 1^{+/+}$(open bars) and sgk1\% (closed bars) DCs. * $(\mathrm{p}<0.05)$, two-tailed unpaired $t$-test.

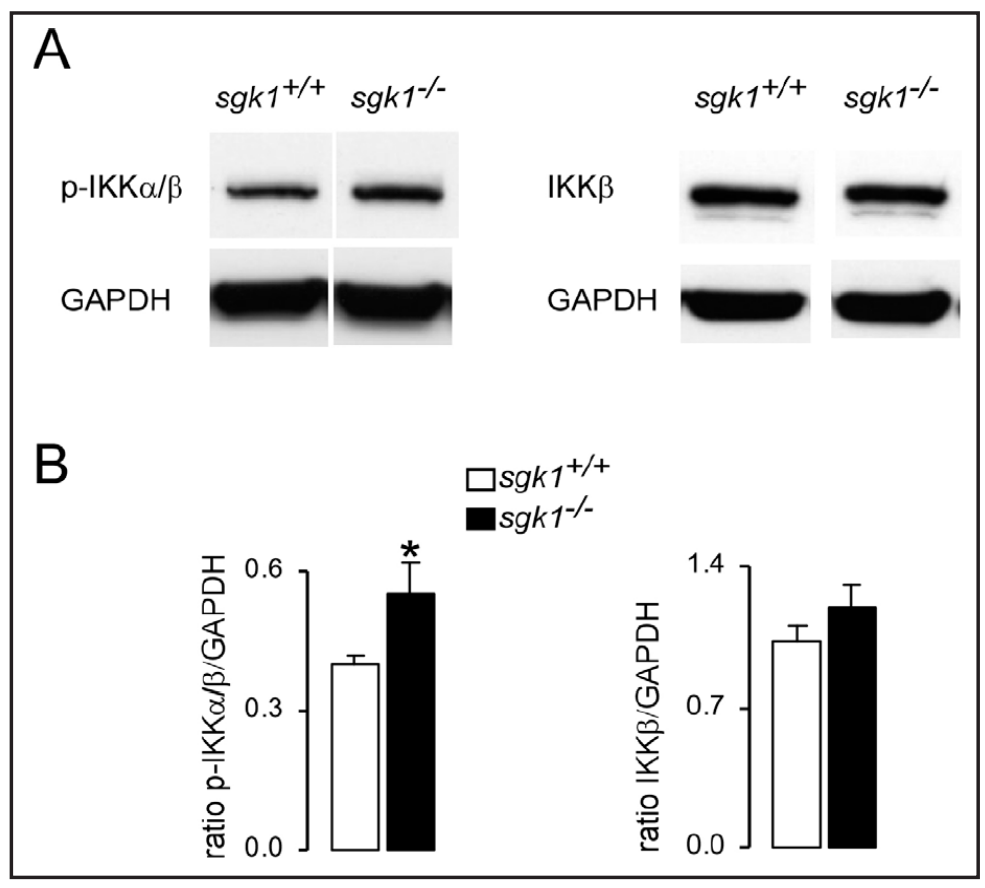

confirmed by real time PCR (Fig. 2C). The increase of nuclear NF- $\kappa B$ subunit p65 following NDRG-1 silencing demonstrates that NDRG-1 is a negative regulator of NF- $\mathrm{KB}$ in DCs.

\section{Loss of SGK1 leads to upregulation of NF- $\kappa B$ signaling}

As shown in Fig. 3, the nuclear localization of p65 was strongly enhanced in $s g k 1 \%$ BMDCs compared to $s g k 1^{+/+}$BMDCs. NDRG1 has been shown to attenuate NF- $\kappa B$ signaling

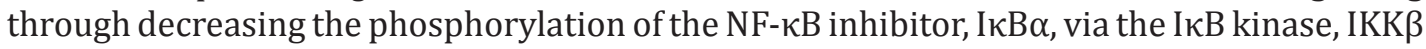
[26]. Phosphorylation of I $\kappa \mathrm{B} \alpha$ at Ser32 and Ser36 leads to its proteosomal degradation that results in the release and nuclear translocation of active NF- $\kappa \mathrm{B}$ [36]. Accordingly, expression and kinase-activating phosphorylation of IKK $\alpha / \beta$ was analyzed in $s g k 1^{+/+}$and $s g k 1 \%$ BMDCs. Expression of IKK $\beta$ was not different between $s g k 1^{+/+}$and $s g k 1 \%$ DCs. However, the abundance of phospho-IKK $\alpha / \beta$ was significantly enhanced in $s g k 1 \%$ BMDCs compared to $s g k 1^{+/+}$BMDCs (Fig. 4). Moreover, the levels of phosphorylated IкB $\alpha$ were significantly higher in $s g k 1 \%$ than in $s g k 1^{+/+}$BMDCs (Fig. 5). 


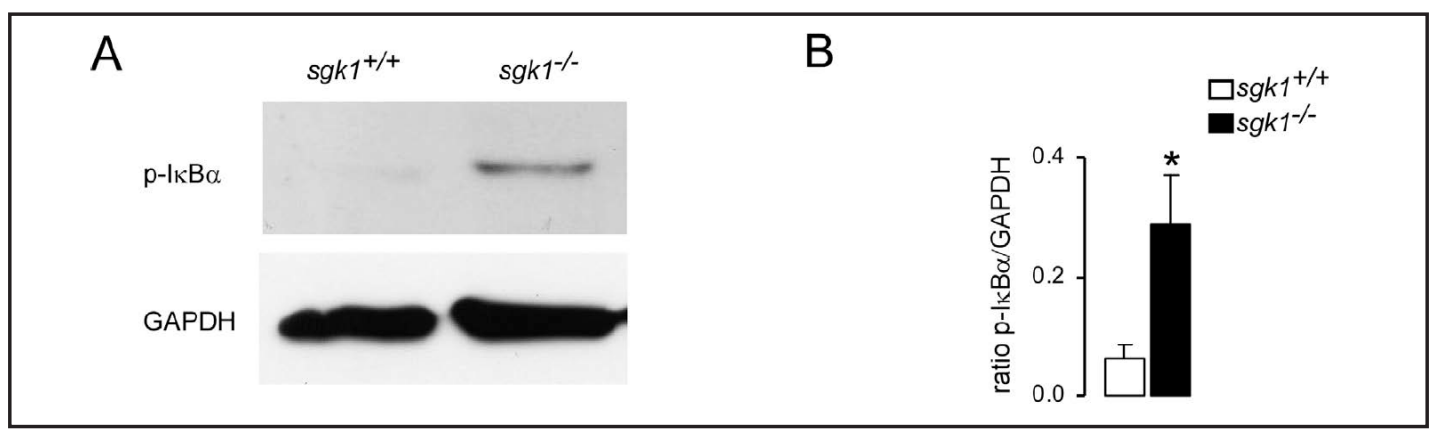

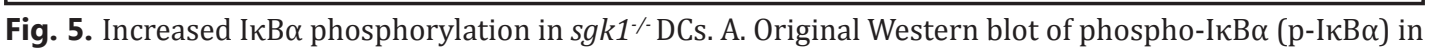
$s g k 1^{+/+}$and $s g k 1^{\%}$ DCs. Protein loading was controlled by anti-GAPDH antibody. B. Arithmetic mean \pm SEM $(\mathrm{n}=4)$ of the abundance of $\mathrm{p}-\mathrm{I} \kappa \mathrm{B} \alpha$ as the ratio to GAPDH in $s g k 1^{+/+}$(open bars) and $s g k 1 \%$ (closed bars) DCs. $*(\mathrm{p}<0.05)$, two-tailed unpaired $t$-test.

A
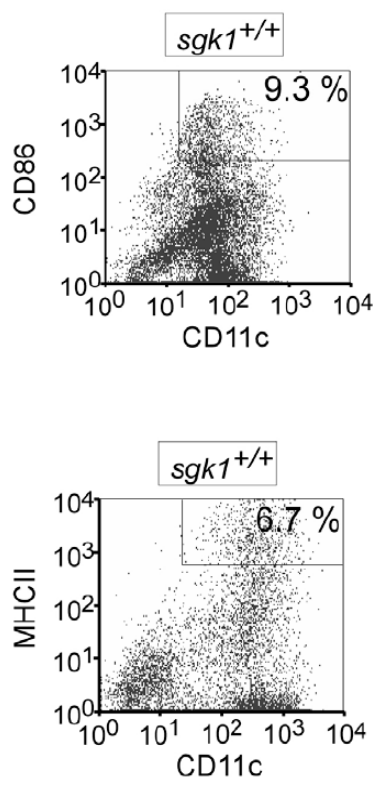

B
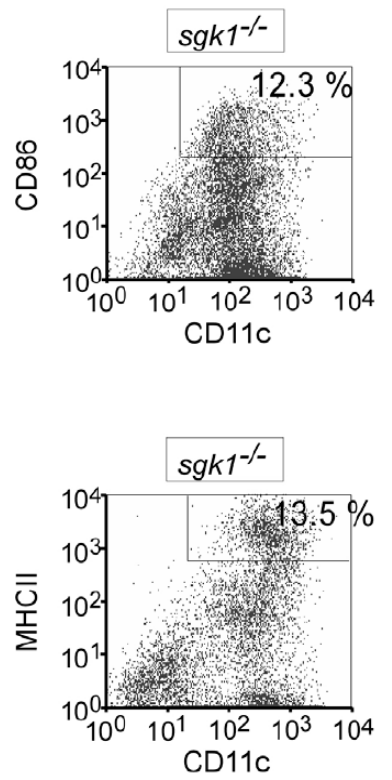

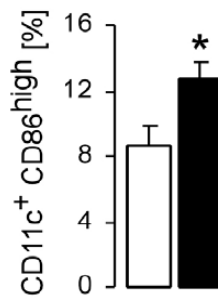

$\square \mathrm{sgk1} 1^{+/+}$ $\square$ sgk $1^{-/-}$

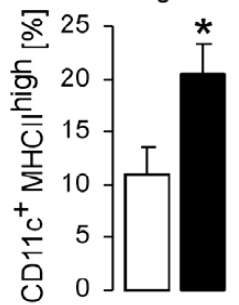

Fig. 6. Enhanced maturation of bone marrow-derived $s g k 1^{\%}$ DCs. A. Original dot plots of CD $11 c^{+} C_{D} 86^{\text {high }}$ (above) and CD11 $\mathrm{c}^{+} \mathrm{MHC}$ II ${ }^{\text {high }}$ (below) DCs from $s g k 1^{+/+}$(left panels) and $s g k 1^{\%}$ (right panels) mice. Numbers depict the percent of cells in the respective quadrants. B. Arithmetic means \pm SEM ( $n=4-5$ DC cultures) of the percentage of CD11 $\mathrm{c}^{+} \mathrm{CD} 86^{\text {high }}$ (above) and CD11 $\mathrm{c}^{+} \mathrm{MHC} \mathrm{II}^{\text {high }}$ (below) DCs in primary cultures from $s g k 1^{+/+}$(open bars) and $s g k 1^{\%}$ (closed bars) mice. * $(\mathrm{p}<0.05)$, two-tailed unpaired $t$-test.

SGK1 deficiency fosters DC differentiation and maturation and reduces their phagocytic capacity

Since NF- $\kappa$ B is essential for DC differention and maturation $[37,38]$, the expression of costimulatory molecule CD86 and MHC class II in $s g k 1^{+/+}$and $s g k 1 \%$ BMDCs was analyzed by FACS analysis. The levels of CD86 and MHC II were higher at the surface of the CD $11 \mathrm{c}^{+}$ gated population obtained from $s g k 1 \%$ mice, if compared to CD11 $\mathrm{c}^{+}$-BMDCs from $s g k 1^{+/+}$ littermates (Fig. 6). Moreover, DCs were isolated from the spleen of $s g k 1^{\%}$ and $s g k 1^{+/+}$mice. Expression of CD86 and MHCII was higher in splenic $s g k 1^{1-}$ DCs than in splenic $s g k 1^{+/+}$DCs (Fig. 7).

The function of DCs as innate immune effectors involves antigen uptake. Thus, we compared the capacity of $s g k 1^{+/+}$and $s g k 1 \%$ BMDCs phagocyting antigen by coincubating 


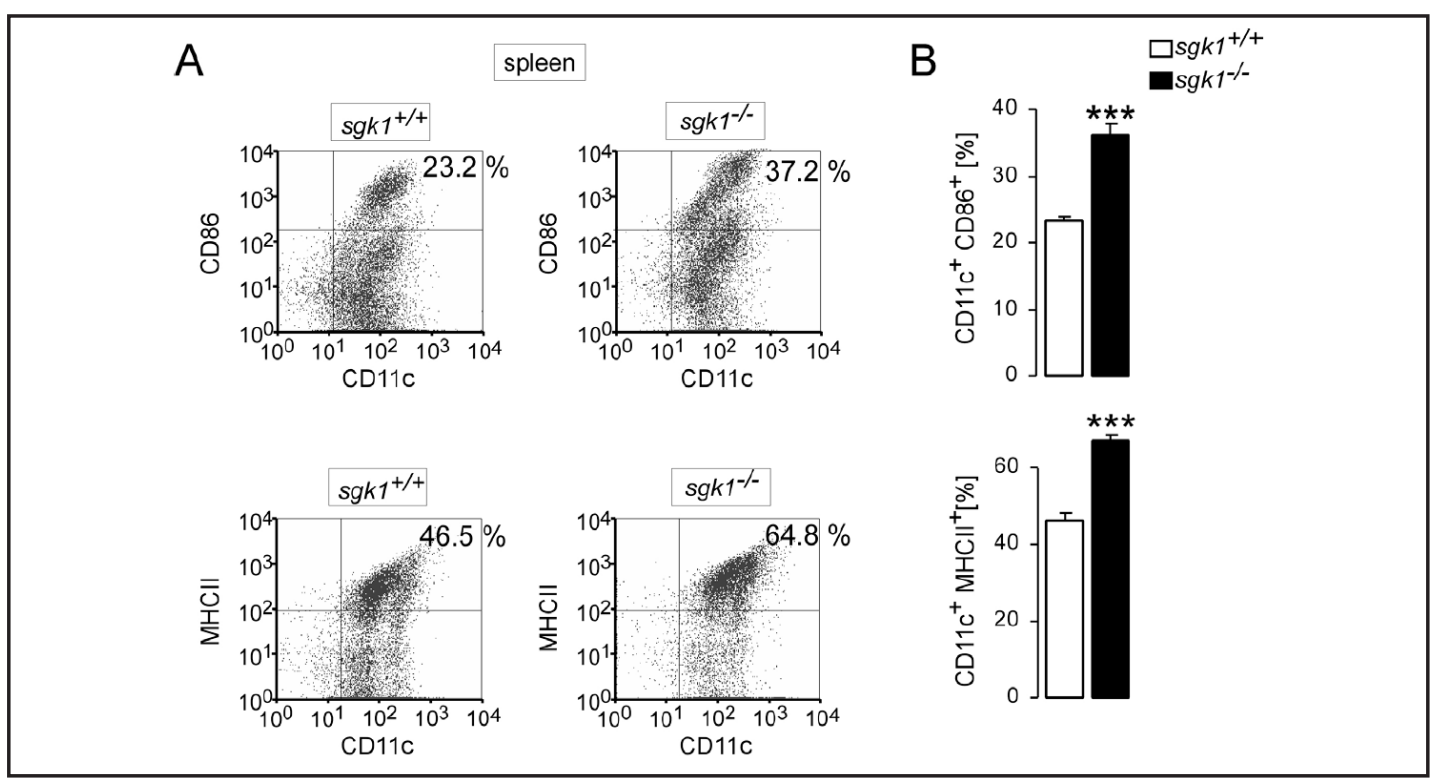

Fig. 7. Increased maturation status of splenic $s g k 1^{\%}$ DCs. A. Original dot plots of CD $11 \mathrm{c}^{+} \mathrm{CD} 86^{+}$(above) and CD $11 \mathrm{c}^{+} \mathrm{MHC} \mathrm{II}^{+}$(below) splenic DCs from $s g k 1^{+/+}$and $s g k 1^{\%}$ mice. Numbers depict the percent of cells in the respective quadrants. B. Arithmetic means \pm SEM ( $n=3-4$ DC cultures) of the percentage of CD $11 c^{+} \mathrm{CD}^{+} 6^{+}$ (above) and CD11 $\mathrm{c}^{+} \mathrm{MHC} \mathrm{II}^{+}$(below) splenic DCs from $s g k 1^{+/+}$(open bars) and $s g k 1^{\%}$ (closed bars) mice. $* * *(\mathrm{p}<0.001)$, two-tailed unpaired $t$-test.

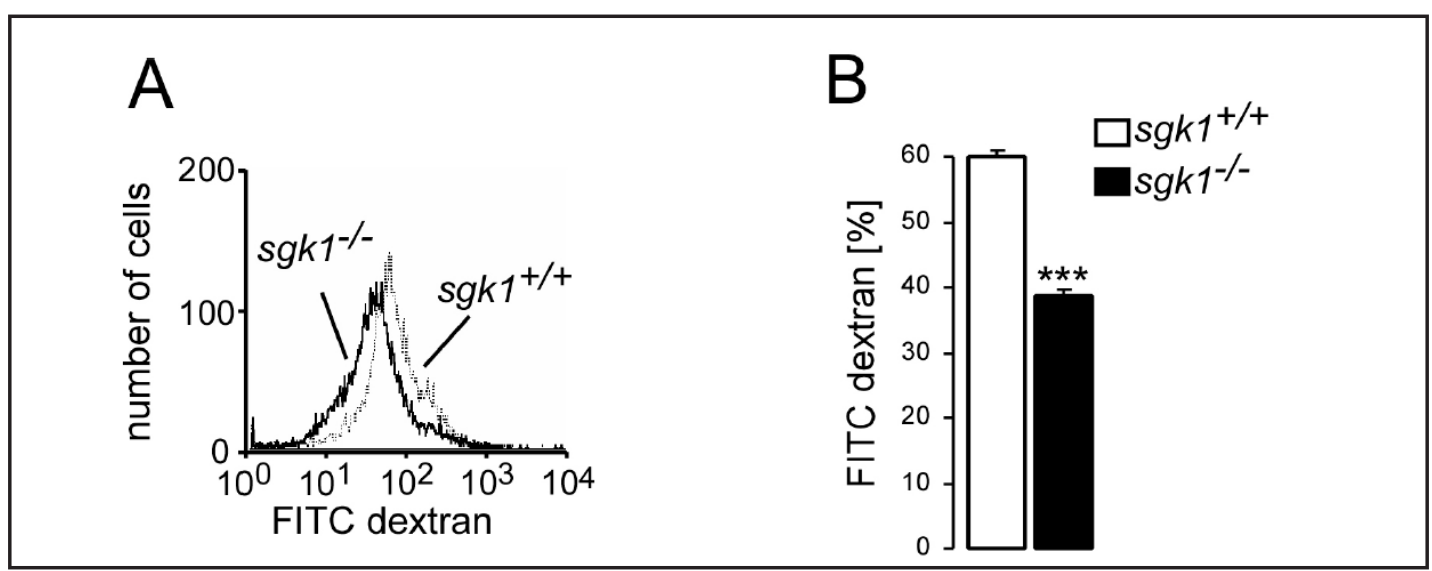

Fig. 8. Impaired phagocytic capacity in $s g k 1 \%$ DCs. A. Histogram representing the percentage of FITCdextran uptake in $s g k 1^{+/+}$and $s g k 1^{\%}$ DCs. B. Arithmetic means \pm SEM $(\mathrm{n}=6)$ of FITC-dextran uptake by $s g k 1^{+/+}$(open bars) and $s g k 1^{\%}$ (closed bars) DCs. ${ }^{* * *}(\mathrm{p}<0.001)$, two-tailed unpaired $t$-test.

BMDCs with FITC-dextran. The phagocytosis of FITC-dextran was found to be significantly reduced in $s g k 1 \%$ BMDCs (Fig. 8), which corresponds well to their enhanced maturation.

\section{Discussion}

According to the present observations lack of SGK1 in dendritic cells (DCs) reduced phosphorylation of NDRG1 and enhanced nuclear translocation of NF- $\kappa B$ (p65 subunit) via suppressing the phosphorylation (and therefore degradation) of the NF- $\kappa B$ inhibitor, IкB $\alpha$, via $\mathrm{I} \kappa \mathrm{B}$ kinase, IKK $\alpha / \beta$. On the other hand, silencing of NDRG-1 in $s g k 1^{+/+} \mathrm{DCs}$ increased nuclear NF$\kappa B$ abundance. Those SGK1-dependent effects substantially influenced maturation and function of DCs. Accordingly, expression of maturation markers was enhanced and phagocytic capacity 
was decreased in $s g k 1^{\%}$ as compared to $s g k 1^{+/+}$DCs. The present observations thus disclose SGK1 as a new major player controlling DC maturation and provide the mechanism of SGK1and NDRG1-dependent NF- $\kappa B$ regulation.

Similar to PKB/Akt, SGK1 is activated through PI3K and phosphoinositide-dependent kinase PDK1 [39-41]. PI3K and PDK1 may function as an endogenous negative feedback that serves to limit excessive innate immune responses [8, 42]. SGK1 could act downstream of PI3K and PDK1 to mediate this negative feedback in DCs.

The nuclear factor- $\mathrm{BB}(\mathrm{NF}-\mathrm{\kappa B}) / \mathrm{REL}$ family of transcription factors plays a central role in coordinating the expression of a wide variety of genes that control immune responses $[43,44]$. PI3K has been shown to negatively regulate NF- $\kappa B$ in human monocyte-derived DCs [15], human monocytes $[17,18]$ and mouse macrophages [16]. IKK $\alpha / \beta$ phosphorylation and

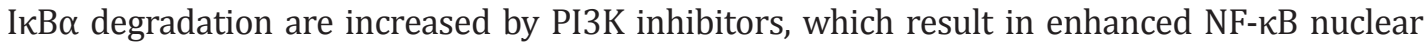
translocation in human DCs [15]. Our data showing enhanced IKK $\alpha / \beta$ and I $\mathrm{I} B \alpha$ phosphorylation and increased p65 nuclear localization in $s g k 1 \%$ DCs provide evidence that SGK1 is involved in the suppressive effect of PI3K on NF- $\kappa \mathrm{B}$ in DCs.

$\mathrm{N}$-myc downstream regulated gene 1 (NDRG1) has been shown to attenuate NF- $\kappa \mathrm{B}$ signaling [26]. In tumor cells overexpressing NDRG1, IKK $\beta$ expression, I $\mathrm{B} \alpha$ phosphorylation, nuclear translocation of p65 and p50 and binding of p65 and p50 to the NF- $\mathrm{kB}$ motif are reduced [26]. Moreover, NDRG1 is a physiological target of SGK1, phosphorylated by SGK1 at Thr328, Ser330 and Thr346 [25]. Phosphorylation of NDRG1 at both Ser330 and Thr346 is required for its suppressive action on the NF- $\mathrm{kB}$ signaling pathway [27].

NDRG1 phosphorylation at Ser330 and Thr346 was strongly reduced in $s g k 1 \%$ DCs. Moreover, silencing of NDRG-1 in $s g k 1^{+/+}$DCs led to enhanced nuclear localization of NF$\kappa B$. Therefore, SGK1 may prevent transport of NF- $\kappa B$ to the nucleus via phosphorylation of NDRG1. NDRG1 has been reported to decrease IKK $\beta$ expression, presumably through proteosomal degradation [26]. However, in $\operatorname{sgk} 1 \%$ DCs phosphorylation of IKK $\alpha / \beta$ but not abundance of total IKK $\alpha / \beta$ protein was enhanced indicating that NDRG1 can presumably regulate IKK $\alpha / \beta$ also through other mechanisms.

In contrast to studies showing that the PI3K pathway negatively regulates expression of inflammatory genes in macrophages and DCs, the PI3K pathway positively regulates NF- $\mathrm{B}$ activity and NF- $\kappa \mathrm{B}$-dependent gene expression in other cell types. Thus, in airway epithelial cells the PI3K-Akt pathway positively regulates NF- $\mathrm{BB}$ transcriptional activity [45]. In 3T3 fibroblasts, overexpression of a constitutively active form of Akt results in NF-kB-dependent gene expression via the activation of IKK and the p38 MAPK [46]. SGK1 has been shown to phosphorylate IKK $\beta$ [47] or IKK $\alpha$ [48], thus promoting degradation of IKB. Moreover, SGK1 increases the acetylation of NF- $\kappa B$ through phosphorylation of $\mathrm{p} 300$, which also leads to NF$\kappa B$ activation [48]. SGK1 is a positive regulator of NF- $\kappa B$ in mast cells [22] and megakaryocytes [21]. Moreover, SGK1 is required for the stimulation and nuclear translocation of NF- $\mathrm{BB}$ following mineralocorticoid excess [23, 24] and thrombin [20]. Thus, SGK1 apparently plays a dual role in the regulation of NF- $\kappa B$, i.e. a IKK dependent upregulation and a NDRG1 dependent downregulation of the transcription factor.

SGK1 seems to be important for maturation of DCs since the expression of CD86 and MHC class II molecules is higher in $s g k 1 \%$ cells. Immature DCs are characterized by a high rate of endocytosis, which rapidly decreases during maturation $[1,6]$. Thus, in accordance to higher expression of maturation markers, $s g k 1 \%$ DCs exhibit reduced phagocytic capacity. This is in agreement with a study on human DCs, showing that pharmacological inhibition of PI3K in DCs results in decreased phagocytosis [49].

SGK1 is under strong genomic stimulation by glucocorticoids [50] and 1,25-dyhydroxyvitamin $\mathrm{D}_{3}$ [51]. Given that both hormones have strong inhibitory effect on DC functions [52-58], it is intriguing to speculate that their mechanism of action in DCs might include upregulation of SGK1.

In conclusion, in mouse DCs genetic knockout of SGK1 leads to reduced phosphorylation of NDRG1, enhanced IKK $\alpha / \beta$ and I $\kappa \mathrm{B} \alpha$ phosphorylation, and enhanced nuclear localization of the NF- $\kappa$ B subunit p65, which presumably fosters maturation of $s g k 1 \%$ DCs. 
Schmid et al.: SGK1 Sensitive Regulation of NF-kB Signaling in DCs

\section{Acknowledgements}

The authors acknowledge the meticulous preparation of the manuscript by Tanja Loch and Sari Rübe. This study was supported by the Deutsche Forschungsgemeinschaft and Open Access Publishing Fund of Tuebingen University.

\section{Disclosures Statement}

The authors state that they do not have any conflict of interests and nothing to disclose.

\section{References}

1 Banchereau J, Briere F, Caux C, Davoust J, Lebecque S, Liu YJ, Pulendran B, Palucka K: Immunobiology of dendritic cells. Annu Rev Immunol 2000;18:767-811.

- Gordon JR, Ma Y, Churchman L, Gordon SA, Dawicki W: Regulatory Dendritic Cells for Immunotherapy in Immunologic Diseases. Front Immunol 2014;5:7.

3 Klechevsky E: Human dendritic cells - stars in the skin. Eur J Immunol 2013;43:3147-3155.

4 Thomas R: Dendritic cells as targets or therapeutics in rheumatic autoimmune disease. Curr Opin Rheumatol 2014;26:211-218.

5 Zinkernagel RM: On the Role of Dendritic Cells Versus Other Cells in Inducing Protective CD8+ T Cell Responses. Front Immunol 2014;5:30.

6 Granucci F, Zanoni I, Feau S, Ricciardi-Castagnoli P: Dendritic cell regulation of immune responses: a new role for interleukin 2 at the intersection of innate and adaptive immunity. EMBO J 2003;22:2546-2551.

7 Fukao T, Tanabe M, Terauchi Y, Ota T, Matsuda S, Asano T, Kadowaki T, Takeuchi T, Koyasu S: PI3K-mediated negative feedback regulation of IL-12 production in DCs. Nat Immunol 2002;3:875-881.

-8 Zaru R, Mollahan P, Watts C: 3-phosphoinositide-dependent kinase 1 deficiency perturbs Toll-like receptor signaling events and actin cytoskeleton dynamics in dendritic cells. J Biol Chem 2008;283:929-939.

-9 Park D, Lapteva N, Seethammagari M, Slawin KM, Spencer DM: An essential role for Akt1 in dendritic cell function and tumor immunotherapy. Nat Biotechnol 2006;24:1581-1590.

10 Yang W, Nurbaeva MK, Schmid E, Russo A, Almilaji A, Szteyn K, Yan J, Faggio C, Shumilina E, Lang F: Akt2- and ETS1-Dependent IP3 Receptor 2 Expression in Dendritic Cell Migration. Cell Physiol Biochem 2014;33:222-236.

11 Kleinewietfeld M, Manzel A, Titze J, Kvakan H, Yosef N, Linker RA, Muller DN, Hafler DA: Sodium chloride drives autoimmune disease by the induction of pathogenic TH17 cells. Nature 2013;496:518-522.

12 Wu C, Yosef N, Thalhamer T, Zhu C, Xiao S, Kishi Y, Regev A, Kuchroo VK: Induction of pathogenic TH17 cells by inducible salt-sensing kinase SGK1. Nature 2013;496:513-517.

13 Lin J, Chang W, Dong J, Zhang F, Mohabeer N, Kushwaha KK, Wang L, Su Y, Fang H, Li D: Thymic stromal lymphopoietin over-expressed in human atherosclerosis: potential role in Th17 differentiation. Cell Physiol Biochem 2013;31:305-318.

14 Zhao H, Li M, Wang L, Su Y, Fang H, Lin J, Mohabeer N, Li D: Angiotensin II induces TSLP via an AT1 receptor/NF-KappaB pathway, promoting Th17 differentiation. Cell Physiol Biochem 2012;30:1383-1397.

15 Aksoy E, Vanden Berghe W, Detienne S, Amraoui Z, Fitzgerald KA, Haegeman G, Goldman M, Willems F: Inhibition of phosphoinositide 3-kinase enhances TRIF-dependent NF-kappa B activation and IFN-beta synthesis downstream of Toll-like receptor 3 and 4. Eur J Immunol 2005;35:2200-2209.

16 Fang H, Pengal RA, Cao X, Ganesan LP, Wewers MD, Marsh CB, Tridandapani S: Lipopolysaccharide-induced macrophage inflammatory response is regulated by SHIP. J Immunol 2004;173:360-366.

17 Guha M, Mackman N: The phosphatidylinositol 3-kinase-Akt pathway limits lipopolysaccharide activation of signaling pathways and expression of inflammatory mediators in human monocytic cells. J Biol Chem 2002;277:32124-32132.

18 Martin M, Schifferle RE, Cuesta N, Vogel SN, Katz J, Michalek SM: Role of the phosphatidylinositol 3 kinaseAkt pathway in the regulation of IL-10 and IL-12 by Porphyromonas gingivalis lipopolysaccharide. J Immunol 2003;171:717-725. 
Schmid et al.: SGK1 Sensitive Regulation of NF-kB Signaling in DCs

19 Fang H, Lin J, Wang L, Xie P, Wang X, Fu J, Ai W, Chen S, Chen F, Zhang F, Su Y, Li D: Kruppel-like factor 2 regulates dendritic cell activation in patients with acute coronary syndrome. Cell Physiol Biochem 2013;32:931-941.

20 BelAiba RS, Djordjevic T, Bonello S, Artunc F, Lang F, Hess J, Gorlach A: The serum- and glucocorticoidinducible kinase Sgk-1 is involved in pulmonary vascular remodeling: role in redox-sensitive regulation of tissue factor by thrombin. Circ Res 2006;98:828-836.

-21 Borst O, Schmidt EM, Munzer P, Schonberger T, Towhid ST, Elvers M, Leibrock C, Schmid E, Eylenstein A, Kuhl D, May AE, Gawaz M, Lang F: The serum- and glucocorticoid-inducible kinase 1 (SGK1) influences platelet calcium signaling and function by regulation of Orai1 expression in megakaryocytes. Blood 2012;119:251-261.

-22 Eylenstein A, Schmidt S, Gu S, Yang W, Schmid E, Schmidt EM, Alesutan I, Szteyn K, Regel I, Shumilina E, Lang F: Transcription factor NF-kappaB regulates expression of pore-forming Ca2+ channel unit, Orai1, and its activator, STIM1, to control Ca2+ entry and affect cellular functions. J Biol Chem 2012;287:2719-2730.

-23 Terada Y, Ueda S, Hamada K, Shimamura Y, Ogata K, Inoue K, Taniguchi Y, Kagawa T, Horino T, Takao T: Aldosterone stimulates nuclear factor-kappa B activity and transcription of intercellular adhesion molecule- 1 and connective tissue growth factor in rat mesangial cells via serum- and glucocorticoidinducible protein kinase-1. Clin Exp Nephrol 2012;16:81-88.

24 Vallon V, Wyatt AW, Klingel K, Huang DY, Hussain A, Berchtold S, Friedrich B, Grahammer F, Belaiba RS, Gorlach A, Wulff P, Daut J, Dalton ND, Ross J, Jr., Flogel U, Schrader J, Osswald H, Kandolf R, Kuhl D, Lang F: SGK1-dependent cardiac CTGF formation and fibrosis following DOCA treatment. J Mol Med (Berl) 2006;84:396-404.

-25 Murray JT, Campbell DG, Morrice N, Auld GC, Shpiro N, Marquez R, Peggie M, Bain J, Bloomberg GB, Grahammer F, Lang F, Wulff P, Kuhl D, Cohen P: Exploitation of KESTREL to identify NDRG family members as physiological substrates for SGK1 and GSK3. Biochem J 2004;384:477-488.

-26 Hosoi F, Izumi H, Kawahara A, Murakami Y, Kinoshita H, Kage M, Nishio K, Kohno K, Kuwano M, Ono M: $\mathrm{N}$-myc downstream regulated gene 1/Cap43 suppresses tumor growth and angiogenesis of pancreatic cancer through attenuation of inhibitor of kappaB kinase beta expression. Cancer Res 2009;69:4983-4991.

27 Murakami Y, Hosoi F, Izumi H, Maruyama Y, Ureshino H, Watari K, Kohno K, Kuwano M, Ono M: Identification of sites subjected to serine/threonine phosphorylation by SGK1 affecting N-myc downstream-regulated gene 1 (NDRG1)/Cap43-dependent suppression of angiogenic CXC chemokine expression in human pancreatic cancer cells. Biochem Biophys Res Commun 2010;396:376-381.

-28 Wulff P, Vallon V, Huang DY, Volkl H, Yu F, Richter K, Jansen M, Schlunz M, Klingel K, Loffing J, Kauselmann G, Bosl MR, Lang F, Kuhl D: Impaired renal $\mathrm{Na}(+)$ retention in the sgk1-knockout mouse. J Clin Invest 2002;110:1263-1268.

29 Yang W, Bhandaru M, Pasham V, Bobbala D, Zelenak C, Jilani K, Rotte A, Lang F: Effect of thymoquinone on cytosolic $\mathrm{pH}$ and $\mathrm{Na}+\mathrm{H}+$ exchanger activity in mouse dendritic cells. Cell Physiol Biochem 2012;29:21-30.

-30 Szteyn K, Schmid E, Nurbaeva MK, Yang W, Munzer P, Kunzelmann K, Lang F, Shumilina E: Expression and functional significance of the $\mathrm{Ca}(2+)$-activated $\mathrm{Cl}(-)$ channel ANO6 in dendritic cells. Cell Physiol Biochem 2012;30:1319-1332.

-31 Rotte A, Pasham V, Bhandaru M, Bobbala D, Zelenak C, Lang F: Rapamycin sensitive ROS formation and $\mathrm{Na}(+) / \mathrm{H}(+)$ exchanger activity in dendritic cells. Cell Physiol Biochem 2012;29:543-550.

32 Stagg AJ, Burke F, Hill S, Knight SC: Isolation of mouse spleen dendritic cells. Methods Mol Med 2001;64:922.

33 Bhandaru M, Pasham V, Yang W, Bobbala D, Rotte A, Lang F: Effect of azathioprine on Na(+)/H(+) exchanger activity in dendritic cells. Cell Physiol Biochem 2012;29:533-542.

-34 Schmid E, Bhandaru M, Nurbaeva MK, Yang W, Szteyn K, Russo A, Leibrock C, Tyan L, Pearce D, Shumilina E, Lang F: SGK3 regulates Ca(2+) entry and migration of dendritic cells. Cell Physiol Biochem 2012;30:14231435.

-35 Schutz SV, Cronauer MV, Rinnab L: Inhibition of glycogen synthase kinase-3beta promotes nuclear export of the androgen receptor through a CRM1-dependent mechanism in prostate cancer cell lines. J Cell Biochem 2010;109:1192-1200.

-36 Karin M, Ben-Neriah Y: Phosphorylation meets ubiquitination: the control of NF-[kappa]B activity. Annu Rev Immunol 2000;18:621-663. 
Schmid et al.: SGK1 Sensitive Regulation of NF-kB Signaling in DCs

37 Burkly L, Hession C, Ogata L, Reilly C, Marconi LA, Olson D, Tizard R, Cate R, Lo D: Expression of relB is required for the development of thymic medulla and dendritic cells. Nature 1995;373:531-536.

38 Wu L, D'Amico A, Winkel KD, Suter M, Lo D, Shortman K: RelB is essential for the development of myeloidrelated CD8alpha- dendritic cells but not of lymphoid-related CD8alpha+ dendritic cells. Immunity 1998;9:839-847.

-39 Alessi DR, Andjelkovic M, Caudwell B, Cron P, Morrice N, Cohen P, Hemmings BA: Mechanism of activation of protein kinase B by insulin and IGF-1. EMBO J 1996;15:6541-6551.

40 Kobayashi T, Cohen P: Activation of serum- and glucocorticoid-regulated protein kinase by agonists that activate phosphatidylinositide 3-kinase is mediated by 3-phosphoinositide-dependent protein kinase-1 (PDK1) and PDK2. Biochem J 1999;339:319-328.

41 Park J, Leong ML, Buse P, Maiyar AC, Firestone GL, Hemmings BA: Serum and glucocorticoid-inducible kinase (SGK) is a target of the PI 3-kinase-stimulated signaling pathway. EMBO J 1999;18:3024-3033.

42 Fukao T, Koyasu S: PI3K and negative regulation of TLR signaling. Trends Immunol 2003;24:358-363.

43 Ardeshna KM, Pizzey AR, Devereux S, Khwaja A: The PI3 kinase, p38 SAP kinase, and NF-kappaB signal transduction pathways are involved in the survival and maturation of lipopolysaccharide-stimulated human monocyte-derived dendritic cells. Blood 2000;96:1039-1046.

44 Li Q Verma IM: NF-kappaB regulation in the immune system. Nat Rev Immunol 2002;2:725-734.

45 Thomas KW, Monick MM, Staber JM, Yarovinsky T, Carter AB, Hunninghake GW: Respiratory syncytial virus inhibits apoptosis and induces NF-kappa B activity through a phosphatidylinositol 3-kinase-dependent pathway. J Biol Chem 2002;277:492-501.

-46 Madrid LV, Mayo MW, Reuther JY, Baldwin AS, Jr.: Akt stimulates the transactivation potential of the RelA/ p65 Subunit of NF-kappa B through utilization of the Ikappa B kinase and activation of the mitogenactivated protein kinase p38. J Biol Chem 2001;276:18934-18940.

47 Zhang L, Cui R, Cheng X, Du J: Antiapoptotic effect of serum and glucocorticoid-inducible protein kinase is mediated by novel mechanism activating I\{kappa\}B kinase. Cancer Res 2005;65:457-464.

48 Tai DJ, Su CC, Ma YL, Lee EH: SGK1 phosphorylation of IkappaB Kinase alpha and p300 Up-regulates NFkappaB activity and increases N-Methyl-D-aspartate receptor NR2A and NR2B expression. J Biol Chem 2009;284:4073-4089.

49 Agrawal A, Agrawal S, Cao JN, Su H, Osann K, Gupta S: Altered innate immune functioning of dendritic cells in elderly humans: a role of phosphoinositide 3-kinase-signaling pathway. J Immunol 2007;178:6912-6922.

50 Firestone GL, Giampaolo JR, O'Keeffe BA: Stimulus-dependent regulation of serum and glucocorticoid inducible protein kinase (SGK) transcription, subcellular localization and enzymatic activity. Cell Physiol Biochem 2003;13:1-12.

51 Akutsu N, Lin R, Bastien Y, Bestawros A, Enepekides DJ, Black MJ, White JH: Regulation of gene Expression by 1alpha,25-dihydroxyvitamin D3 and Its analog EB1089 under growth-inhibitory conditions in squamous carcinoma Cells. Mol Endocrinol 2001;15:1127-1139.

52 Griffin MD, Dong X, Kumar R: Vitamin D receptor-mediated suppression of RelB in antigen presenting cells: a paradigm for ligand-augmented negative transcriptional regulation. Arch Biochem Biophys 2007;460:218-226.

-53 Heise N, Shumilina E, Nurbaeva MK, Schmid E, Szteyn K, Yang W, Xuan NT, Wang K, Zemtsova IM, Duszenko M, Lang F: Effect of dexamethasone on $\mathrm{Na}+/ \mathrm{Ca} 2+$ exchanger in dendritic cells. Am J Physiol Cell Physiol 2011;300:C1306-1313.

54 Lyakh LA, Sanford M, Chekol S, Young HA, Roberts AB: TGF-beta and vitamin D3 utilize distinct pathways to suppress IL-12 production and modulate rapid differentiation of human monocytes into CD83+ dendritic cells. J Immunol 2005;174:2061-2070.

55 Penna G, Amuchastegui S, Laverny G, Adorini L: Vitamin D receptor agonists in the treatment of autoimmune diseases: selective targeting of myeloid but not plasmacytoid dendritic cells. J Bone Miner Res 2007;22 Suppl 2:V69-73.

56 Shumilina E, Xuan NT, Matzner N, Bhandaru M, Zemtsova IM, Lang F: Regulation of calcium signaling in dendritic cells by 1,25-dihydroxyvitamin D3. FASEB J 2010;24:1989-1996.

57 van Etten E, Mathieu C: Immunoregulation by 1,25-dihydroxyvitamin D3: basic concepts. J Steroid Biochem Mol Biol 2005;97:93-101.

58 Yamaguchi Y, Tsumura H, Miwa M, Inaba K: Contrasting effects of TGF-beta 1 and TNF-alpha on the development of dendritic cells from progenitors in mouse bone marrow. Stem Cells 1997;15:144-153. 